\title{
INFLUÊNCIA DO TESTE AERÓBIO MÁXIMO NO SALTO VERTICAL EM ATLETAS COM PARALISIA CEREBRAL.
}

\author{
Vitor T. P. Nardi*, Fernando R. de Faria, José I. Gorla.
}

\section{Resumo}

A potência é uma das capacidades mais importantes para um jogador de futebol, principalmente nos momentos que decidem o jogo. A mesma também é no futebol de 7, praticado por atletas com paralisia cerebral (PC). Objetivou-se com este estudo comparar o índice de potência de membros inferiores obtida antes e após teste aeróbio máximo. $O$ estudo foi composto pela realização de 3 saltos de Squat Jump (SJ) e Countermovement Jump (CMJ) com 10 segundos de recuperação passiva entre cada salto, já para o teste aeróbio máximo o teste Yo-Yo IRT1 consistiu na realização de corridas bidirecionais de $2 \times 20 \mathrm{~m}$ com recuperação ativa de $10 \mathrm{~s}$ a cada $40 \mathrm{~m}$. Os resultados apontaram para correlações altas quando comparados os valores absolutos da altura, potência e potência por quilograma, tanto do SJ quanto do CMJ. Então conclui-se que o desempenho de saltos verticais pós teste aeróbio máximo, tanto o SJ quanto o CMJ foram inferiores aos realizados previamente.

Palavras-chave: Futebol, Paralisia Cerebral, SaltoVertical.

\section{Introdução}

O futebol é um esporte caracterizado por atividades intermitentes, o qual exige grande demanda física, o que requer uma apurada habilidade técnica, força, velocidade, agilidade e potência. $\mathrm{O}$ mesmo ocorre no futebol de 7, que é praticado por atletas com paralisia cerebral (PC) ou deficiências associadas como sequelas de traumatismo crânio-encefálico ou acidentes vasculares cerebrais (IFCPF, 2018a). A paralisia cerebral é uma síndrome e comprometimento motor que resulta de uma lesão que ocorre no cérebro em desenvolvimento, o distúrbio varia no momento da lesão, na apresentação clínica e no local e gravidade das deficiências. As diferentes manifestações da PC podem acarretar ao jogador déficits de força e consequentemente prejuízo na potência muscular tendo em conta as demandas exigidas durante uma partida de futebol de 7

A utilização de um teste de esforço máximo, como - Yo Yo Intermittent Recovery Test, a fim de simular a fadiga a qual estimula a avaria das habilidades do futebol no curso de uma partida (IMPELLIZZERI et al., 2008; RAMPININI et al., 2010) e aplicação de salto vertical com o intuito de mensurar a potência de membros inferiores apresentam-se como mecanismos adequados para avaliação de atletas com paralisia cerebral. Assim verificar a influência do teste aeróbio máximo no salto vertical em atletas com paralisia cerebral do futebol de 7 .

\section{Resultados e Discussão}

O teste consistiu na realização dos saltos: Squat Jump (SJ) e Countermovement Jump (CMJ) (Bosco, Luhtanen, Komi, 1983). O protocolo foi constituído da realização de 3 saltos para cada teste com 10 segundos de recuperação passiva entre cada salto.

$\mathrm{O}$ objetivo do presente estudo foi verificar a influência do teste aeróbio máximo no salto vertical em atletas com paralisia cerebral do futebol de 7. Os resultados encontrados demonstraram diferença significativa pré e pós teste aeróbio máximo, demonstrado na tabela 1.
Tabela 1. Mensurações dos saltos verticais pré e pós Yo-Yo recovery test level 1.]

\begin{tabular}{ccccc} 
& & Pré & Pós & p-valor \\
\hline SJ & $A L T$ & $33,8 \pm 6,9$ & $30,2 \pm 5,6$ & 0,002 \\
& $P O T$ & $3303,9 \pm 465$, & $3086,6 \pm$ & 0,002 \\
& & 5 & 397,8 & \\
& $P O T / K G$ & $45,3 \pm 5,6$ & $42,3 \pm 4,6$ & 0,002 \\
CMJ & $A L T$ & $35,0 \pm 6,5$ & $32,1 \pm 6,6$ & 0,008 \\
& $P O T$ & $3375,1 \pm 400$, & $3198,8 \pm$ & 0,008 \\
& & 0 & 396,2 & \\
& $P O T / K G$ & $46,4 \pm 5,3$ & $44,0 \pm 5,4$ & 0,008
\end{tabular}

Legenda: SJ - Squat jump; CMJ - Couter Moviment Jump; ALT - Altura ; POT - Potência; POT/Kg -

Potência/Quilograma; Nível de significância $p<0,05$.

\section{Conclusões}

Conclui-se que o desempenho de saltos verticais pós teste aeróbio máximo, tanto o squat jump quanto o counter movement jump, foram significativamente inferiores aos realizados previamente. Através deste estudo podemos identificar que 0 desgaste físico ocasionado pelo exercício máximo causou influência negativa e significativa na potência dos membros inferiores, indicando a necessidade de uma melhor manutenção do condicionamento físico a fim de minimizar o impacto no desempenho.

Pibic, Unicap, CNPQ.

\section{Agradecimentos}

BOSCO, C; LUHTANEN, P; KOMI, P. V. A simple method for measurement of mechanical power in jumping. European journal of applied physiology and occupational physiology, v. 50, n. 2, p. 273-282, 1983.

IFCPF. Modifications to the Laws of the Game. International Federation of CP Football, January, p. 1-8, 2018b. Disponível em: https://www.ifcpf/static/upload/raw/b669a53f-79f1-492a-8c8a-

8608d06f2030/IFCPF+-+Modifications+to+the+Laws+of+the+Game++2018.pdf.

IMPELLIZZERI, F. M. et al. Validity of a repeated-sprint test for football International journal of sports medicine, v. 29, n. 11, p. 899-905, 2008. 